\title{
Chiral Recognition of Binaphthyl Derivatives with L-Undecyl Leucine Surfactants in the Presence of Sodium and Lysine Counterions
}

\author{
Mauro Garcia1 ${ }^{1}$ Amanda Risley¹, Fereshteh Billiot1*, Eugene Billiot ${ }^{1}$, Kevin Morris ${ }^{2}$ \\ ${ }^{1}$ Department of Physical and Environmental Sciences, Texas A\&M University-Corpus Christi, Corpus Christi, USA \\ ${ }^{2}$ Department of Chemistry, Carthage College, Kenosha, USA \\ Email: ^fereshteh.billiot@tamucc.edu
}

How to cite this paper: Garcia, M., Risley, A., Billiot, F., Billiot, E. and Morris, K. (2021) Chiral Recognition of Binaphthyl Derivatives with L-Undecyl Leucine Surfactants in the Presence of Sodium and Lysine Counterions. American Journal of Analytical Chemistry, 12, 188-201. https://doi.org/10.4236/ajac.2021.125012

Received: February 24, 2021

Accepted: May 28, 2021

Published: May 31, 2021

Copyright $\odot 2021$ by author(s) and Scientific Research Publishing Inc. This work is licensed under the Creative Commons Attribution International License (CC BY 4.0).

http://creativecommons.org/licenses/by/4.0/

\begin{abstract}
This study investigates the effect of counterions on the chiral recognition of 1,1'-Binaphthyl-2,2'-diamine (BNA) and 1,1'-Binaphthyl-2,2'-diyl hydrogenphosphate (BNP) enantiomers when using an amino acid-based surfactant undecanoyl L-leucine (und-Leu) as the chiral pseudostationary phase in capillary electrophoresis. The effects of using two different counterions (sodium and lysine) on the chiral recognition of binaphthyl derivatives were compared at varying $\mathrm{pH}$ conditions. The enantiomeric separation of BNA and BNP enantiomers via capillary electrophoresis, using und-Leu as the chiral recognition medium, significantly improved the enantiomeric resolution in capillary electrophoresis at $\mathrm{pH} 7$ when using Lysine counterions as compared to using sodium as the counterion. More specifically, at a surfactant concentration of $45 \mathrm{mM}$, at $\mathrm{pH} \mathrm{7}$, a significant increase in chiral selectivity was observed when lysine was used as the counterion compared to sodium. The enantiomeric resolution of BNA and BNP increased by 6-fold and 1.1-fold, respectively, in capillary electrophoresis experiments when lysine was utilized as the counterion compared to using sodium. Furthermore, the retention factor of BNA and BNP enantiomers also increased approximately 3.5-fold and 4-fold, respectively, in the presence of lysine counterions as compared to using sodium counterions. When running buffer in capillary electrophoresis was increased to $\mathrm{pH} 11$, the resolution and retention factors were nearly identical when comparing the effects of the sodium and lysine counterions. This signifies the important role of lysine's positive net charge on chiral recognition. This study provides insight into the potential advantages of using cationic, $\mathrm{pH}$-dependent counterions such as lysine to significantly improve the chiral recognition of binaphthyl derivatives when using chiral anionic surfactants as the pseudostationary phase in capillary electrophoresis.
\end{abstract}




\section{Keywords}

Lysine, Binaphthyl, Counterions, Chiral Recognition, Amino Acid-Based Surfactants, Micellar Electrokinetic Chromatography

\section{Introduction}

Chirality is ubiquitous in nature. Two of the most important simple class of chiral compounds include amino acids and sugars. Sugars and amino acids serve as the building blocks for a large percentage of biological compounds [1]-[6]. This suggests the profound influence of chirality on fundamental physiological and biological processes. Furthermore, stereospecific reactions play an essential role in drug metabolism, cell membrane stability, and gene expression [7]-[12].

Due to the aforementioned stereospecific reactions that occur within the body, it is not surprising that more than $50 \%$ of marketed drugs are chiral [13] [14] [15] [16]. These synthesized pharmaceutical drugs, however, frequently yield racemic mixtures, meaning it contains both enantiomers. This is of major concern because each enantiomer of a drug may exhibit different pharmacological effects. For example, the drug Thalidomide was originally marketed as a racemic mixture and administered to women to help mitigate the effects of morning sickness during pregnancy. Relatively soon after bringing this drug onto the market, an alarming rise in birth defects in newborns was observed. It was later determined that while one enantiomer caused the beneficial pharmaceutical effects, the other enantiomer was the cause of the teratogenic effects [17] [18]. In response to this tragedy, the Food and Drug Administration has mandated that each enantiomer of a chiral drug be evaluated for its respective physiological effects prior to being marketed [13] [16] [19] [20] [21] [22] [23]. This gave rise to a new scientific challenge: to establish and optimize enantiomeric separation processes and techniques.

Since then, many techniques have been established to separate enantiomeric compounds. Two of the more common techniques are high-performance liquid chromatography (HPLC) and capillary electrophoresis (CE) [19] [21] [24] [25] [26] [27]. CE typically yields a higher number of theoretical plates compared to HPLC and thus CE often yields better enantiomeric separations in a shorter period of time [28] [29]. In addition, CE allows for a quick and easy way to change the chiral recognition medium since the chiral recognition medium is part of the mobile phase acting as a pseudo-stationary phase. This is in contrast to HLPC which requires the purchase and installation of different analytical columns if one wishes to change the chiral recognition medium. With HPLC, a wide variety of chiral recognition media exist including but not limited to cyclodextrins, crown ethers, and chiral micelles [21] [24] [25] [26] [27]. This research focuses on the latter, chiral micelles. 
In particular, the chiral micelles described in this article are amino acid-based micelles (AABMs). It is worth noting that when micelles are used as the pseudostationary phase in $\mathrm{CE}$, the technique is known as micellar electrokinetic chromatography (MEKC). MEKC is a well-established technique for the enantiomeric separation of chiral compounds [21] [24] [25] [26] [30] [31] [32] [33] [34]. Amino acid-based surfactants are composed of a non-polar hydrocarbon chain and an amino acid head group [35]-[40]. The charge on the amino acid head groups can be greatly influenced by $\mathrm{pH}$ levels. The ability to impose different $\mathrm{pH}$ environments aids in studying how the charge of the surfactant, analytes, and counterions may affect the physiochemical properties of the micelles, as well as its ability to act as an effective chiral separation medium [30] [34]. All of which greatly influence the chiral recognition ability of the AABMs.

Previously, the effects of amino acid order, steric hindrance, dihedral angles, and the polymerization of AABMs have been studied experimentally and computationally to investigate their contributions to chiral recognition [21] [30] [31] [32] [33]. For many years, sodium has been extensively used as the counterion for the MEKC buffer solution [21] [22] [30] [31] [32] [33] [34]. Recently, the effects of $\mathrm{pH}$-dependent counterions have been used to significantly improve the resolution of enantiomeric compounds in MEKC [30] [34]. As previously reported from our research group, $\mathrm{pH}$-dependent counterions, such as arginine have been demonstrated to significantly improve the enantiomeric resolution of various binaphthyl derivatives, when compared to using monatomic sodium as the counterion [34].

To further investigate the effects of $\mathrm{pH}$-dependent counterions on chiral selectivity, this study investigates the role of lysine as the counterion on the chiral separations of 1,1'-Binaphthyl-2,2'-diyl hydrogenphosphate (BNP) and 1,1'Binaphthyl-2,2'-diamine (BNA) enantiomers at $\mathrm{pH} 7$ and 11 at varying concentrations of und-Leu surfactant. The structures of the surfactant, analytes, and lysine are provided in Figure 1. As shown in this figure, lysine contains two amine groups; one connected to the chiral carbon and another as a side chain substituent, which contains pKa values of approximately 9 and 10.5, respectively. As shown in Figure 2, lysine has various charge states at different $\mathrm{pH}$ levels. The various charge states can have a significantly different effect on the physicochemical properties and chiral recognition ability of the micelles formed. However, due to the solubility limitations of the micelles, we cannot work below $\mathrm{pH} 7$, nor above $\mathrm{pH} 11$ due to the limitations of capillary electrophoresis. Therefore, we limited our experiments to the useful $\mathrm{pH}$ extremes of our system, $\mathrm{pH} 7$ and 11.

\section{Methods}

\section{Chemicals}

Leucine, lysine and racemic mixtures of binaphthyl derivatives [1,1'-Binaphthyl2,2'-diyl hydrogenphosphate (BNP) and 1,1'-Binaphthyl-2,2'-diamine (BNA)] were 
purchased from Sigma-Aldrich (St. Louis, MO). The und-Leu surfactant was synthesized from the $\mathrm{N}$-hydroxysuccinimide ester of undecylenic acid according to a previously reported procedure [34] [41].

\section{Capillary electrophoresis procedure}

Chiral separations were performed using a Hewlett-Packard (HP) 3D CE model \#G7100A. The fused silica capillary [effective length of $45 \mathrm{~cm}$ (to detection window), $50-\mu \mathrm{m}$ i.d., with a total length of $56 \mathrm{~cm}$ ] was purchased from Agilent Technologies (Lake Jackson, TX) and mounted in an HP capillary cartridge. The temperature of the cartridge was maintained at $25^{\circ} \mathrm{C}$ throughout these experiments. Solutions of $45 \mathrm{mM}$ und-Leu with lysine and sodium were prepared in a $5 \mathrm{mM}$ sodium borate buffer and $\mathrm{pH}$ was adjusted to values of 7 and 11 with the use of $\mathrm{NaOH}$ and $\mathrm{HCl}$. These solutions were diluted to concentrations ranging from 15 to $45 \mathrm{mM}$ and filtered through a $0.45-\mu \mathrm{m}$ syringe filter before use. Analyte standards were prepared in 1:1 methanol-water at $0.1 \mathrm{mg} / \mathrm{mL}$. Samples were injected for $5 \mathrm{~s}$ at 10 mbar pressure. Separations were performed at $+30 \mathrm{kV}$, with UV detection at $230 \mathrm{~nm}$.

\section{Results and Discussion}

In this study, the chiral recognition of und-Leu at varying concentrations in the

(a)<smiles>C=CCCCCCCCCC(=O)NC(CC(C)C)C(=O)O</smiles>

(b)

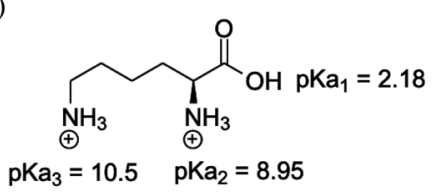

(c)

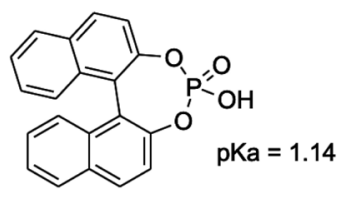

(d)

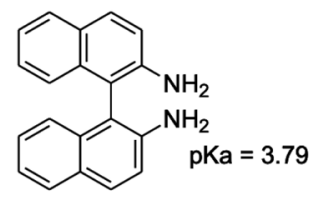

Figure 1. Structure of (a) L-Undecyl-Leucine surfactant (b) Lysine (c) BNP (d) BNA.<smiles>[NH3+]CCCC[C@@H]([NH3+])C(=O)O</smiles>

Net charge: $2+$<smiles>[NH3+]CCCC[C@H]([NH3+])C(=O)[O-]</smiles>

Net charge: $1+$

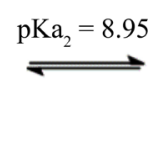<smiles>CNCCCC[C@H](N)C(=O)[O-]</smiles>

Net charge: 0<smiles>NCCCCC(N)C(=O)[O-]</smiles>

Net charge: 1-

Figure 2. Representation of the charged states and isoelectric point of Lysine. 
presence of sodium and L-lysine counterions was investigated at $\mathrm{pH} 7$ and 11. We separated the enantiomers of BNP and BNA with varying concentrations of surfactant ranging from 15 to $45 \mathrm{mM}$, with $5 \mathrm{mM}$ concentration intervals. As shown in Figure 3(a), $\mathrm{pH} 7$ provided a better resolution for separating BNP enantiomers in the presence of lysine as compared to sodium. The retention factor $\left(k^{\prime}\right)$ values shown in Figure 3(b) indicate that at $\mathrm{pH} 7$, the enantiomers of BNP interacted stronger when lysine was used as the counterion compared to sodium. At $\mathrm{pH} 7$ and a surfactant concentration of $45 \mathrm{mM}$, the $\mathrm{k}$ ' value for BNP was $\sim 5.8$, whereas this value was $\sim 1.2$ in the presence of sodium. As $\mathrm{pH}$ increased to 11, the retention factor for the enantiomers of BNP was similar in the presence of both counterions-lysine and sodium.

The resolution and retention factors for the enantiomers of BNA in the presence of lysine and sodium counterions are shown in Figure 4. At $\mathrm{pH}$ 7, with und-Leu concentration of $15 \mathrm{mM}$, in the presence of lysine, the enantiomers of BNA were separated with a resolution of $\sim 1.8$, whereas at the same concentration
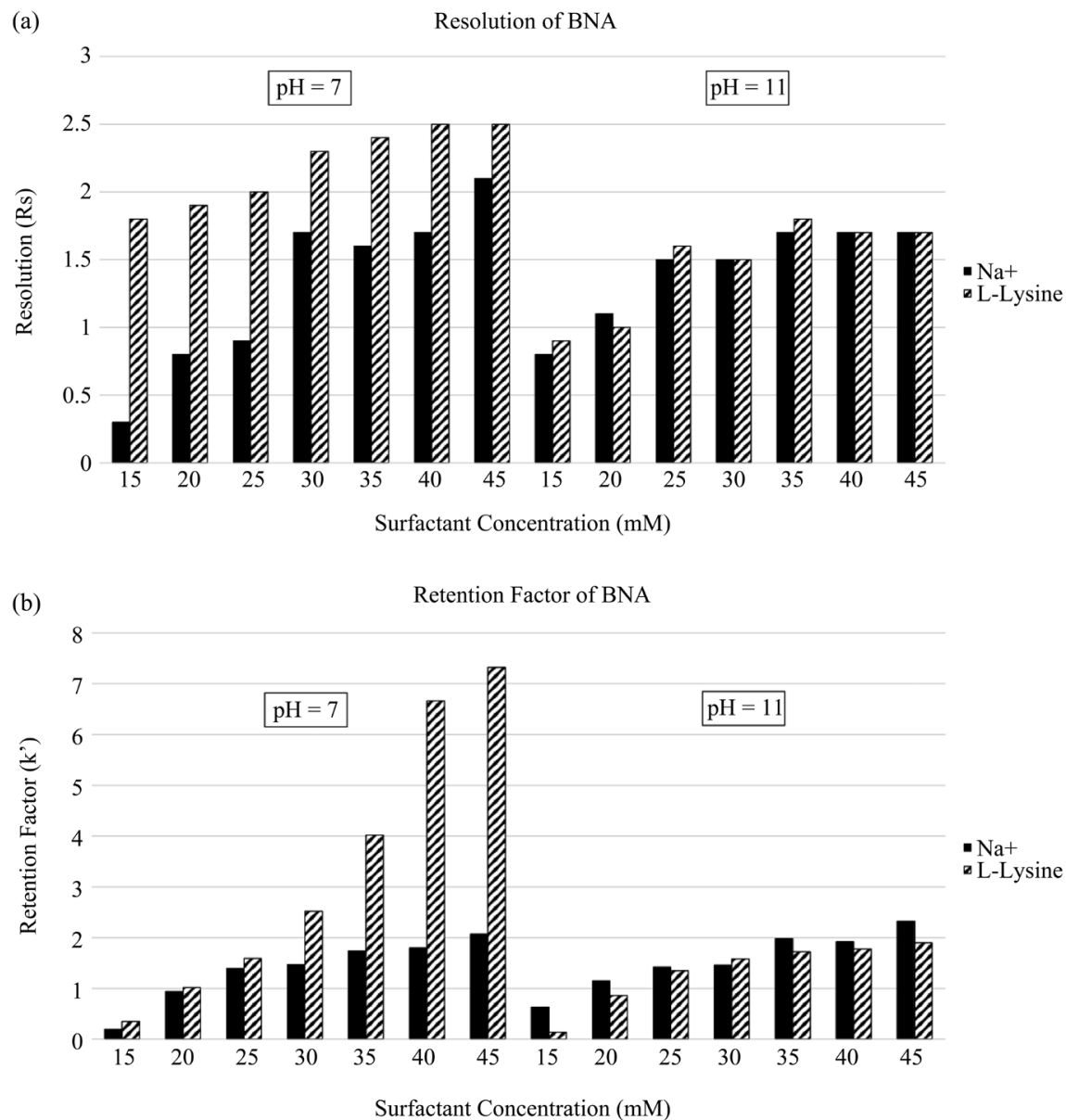

Figure 3. Comparison of the (a) resolution of BNP enantiomers (average std $= \pm 0.1$ ) and (b) k' of BNP enantiomers in the presence of $\mathrm{Na}+$ and L-Lysine counterions (average std $= \pm 0.02$ ), at concentrations of und-Leu ranging from $15 \mathrm{mM}$ to $45 \mathrm{mM}$ (in $5 \mathrm{mM}$ increments), at $\mathrm{pH} 7$ and 11 . UV detection is at $230 \mathrm{~nm}$, applied voltage was at $+30 \mathrm{kV}$, and capillary temperature at $25^{\circ} \mathrm{C}$. 

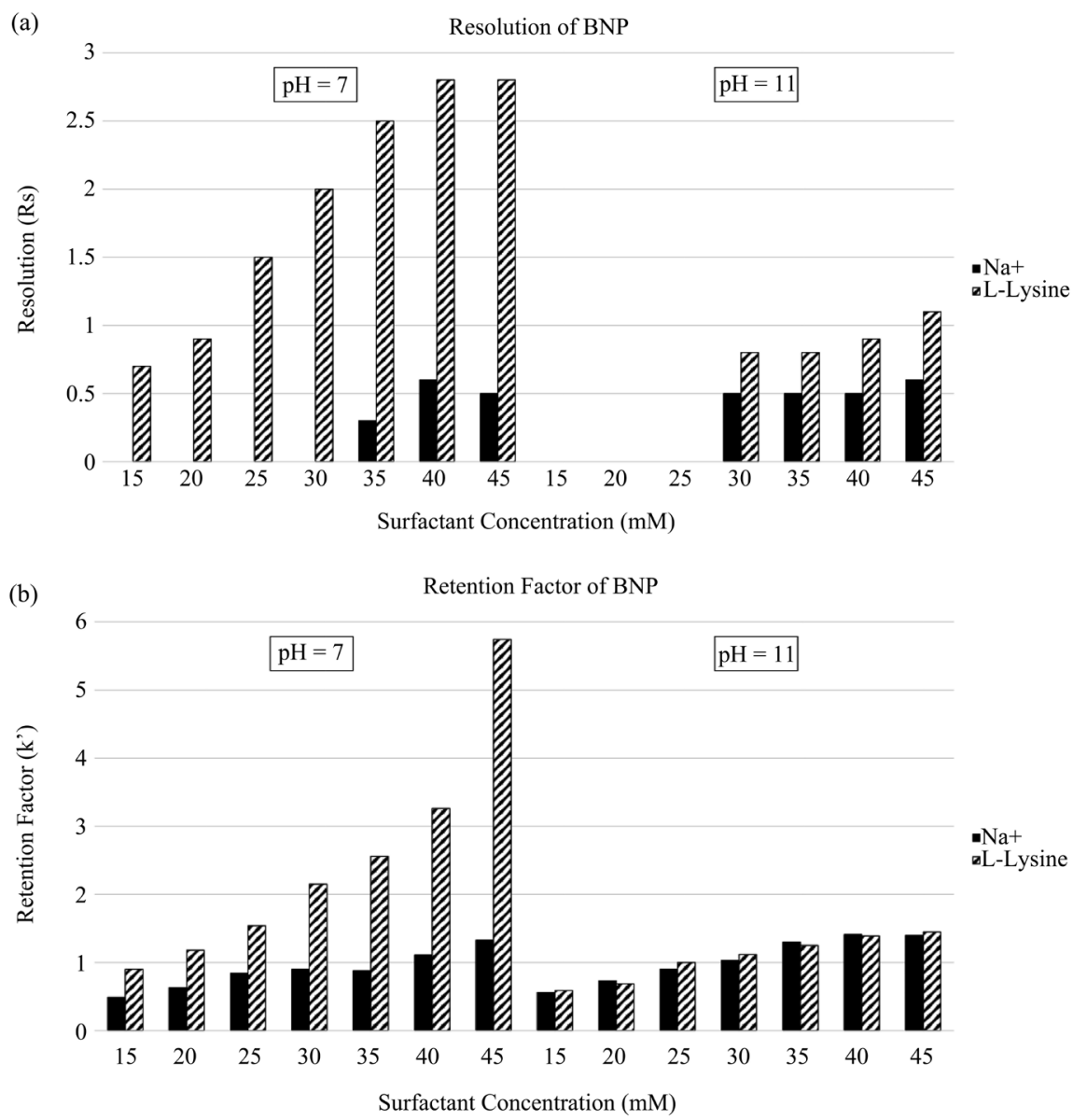

Figure 4. Comparison of the (a) resolution of BNA enantiomers (average std $= \pm 0.1$ ) and (b) k' of BNA enantiomers in the presence of $\mathrm{Na}+$ and L-Lysine counterions (average std $= \pm 0.04$ ), at concentrations of und-Leucine ranging from $15 \mathrm{mM}$ to $45 \mathrm{mM}$ (in $5 \mathrm{mM}$ increments), at $\mathrm{pH} 7$ and 11 . UV detection is at $230 \mathrm{~nm}$, applied voltage was at $+30 \mathrm{kV}$, and capillary temperature at $25^{\circ} \mathrm{C}$.

and $\mathrm{pH}$, a resolution of $\sim 0.4$ was observed in the presence of sodium. Similar to $\mathrm{BNP}$, at higher $\mathrm{pH}$ levels, the resolution and retention factors for BNA were approximately the same for both, sodium and lysine counterions. Shown in Figure 5 is an electropherogram comparing the separation of BNP enantiomers at $\mathrm{pH} 7$ and $25 \mathrm{mM}$ in the presence of sodium and lysine. As can be seen in Figure 5(a), no separation was achieved with sodium as the counterion but as shown in Figure 5(b), a resolution of $\sim 1.5$ was achieved when lysine was used as the counterion.

Chiral recognition with amino acid-based surfactants is strongly dependent on molecular interactions such as: hydrogen bonding, electrostatic attraction, steric hindrance and the hydrophobic effect. Surfactants with amino acid head groups contain amide and carboxylic acid moieties, in which the $\mathrm{pH}$ is expected to affect the electrostatic and hydrogen bonding capabilities of the polar head constituents of the surfactants. A previous study by Ramos et al. investigated the effects of chiral recognition of und-Leu surfactant in the presence of arginine 

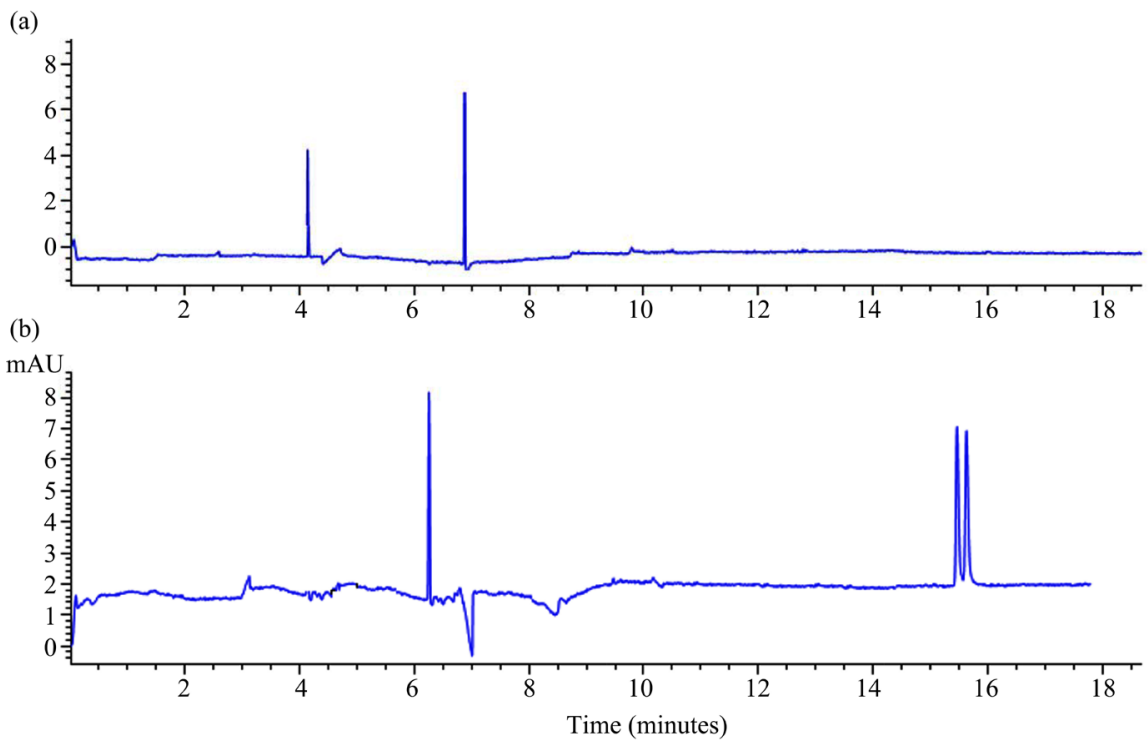

Figure 5. Electropherogram of BNP at $\mathrm{pH} 7$ and surfactant concentration of $25 \mathrm{mM}$ comparing separations in the presence of (a) sodium counterions and (b) Lysine counterions. UV detection is at $230 \mathrm{~nm}$, applied voltage was at $+30 \mathrm{kV}$, and capillary temperature at $25^{\circ} \mathrm{C}$.

and sodium counterions [34]. In Ramos et al., the BNP enantiomers were separated via MEKC at $\mathrm{pH} 7$ in the presence of arginine and sodium, with resolutions of approximately 4.1 and 0.6 , respectively [34]. When sodium was used as the counterion, baseline resolution of BNP was not observed. Results of that study suggest that the counterion plays a significant role in chiral recognition with amino acid-based surfactants. This motivates the current investigation of comparing the effect of $\mathrm{pH}$ on chiral recognition of BNP and BNA enantiomers with und-Leu surfactants in presence of lysine and sodium counterions.

As previously discussed, lysine contains two amine groups; one amine group is directly connected to the chiral carbon and another amine group on the side chain of the molecule. As also previously mentioned, at lower $\mathrm{pH}$ levels both of the amine moieties are protonated, providing lysine with a net positive charge, as shown in Figure 2. This net positive charge on lysine allows it to act as a counterion for the negatively charged amino acid-based surfactants. The presence of amine groups on lysine allows for hydrogen bonds and electrostatic attraction to occur with the BNP and BNA enantiomers, as well as with the surfactant polar head group. These intermolecular interactions cannot occur with sodium counterions as it is monatomic and does not contain hydrogen bonding moieties. As previously reported, the amount of lysine molecules bound to the surfactant (fraction bound, $\mathrm{f}_{\mathrm{b}}$ ) changes significantly as a function of $\mathrm{pH}$ [30] [34]. At $\mathrm{pH} \mathrm{7,} \mathrm{37 \%} \mathrm{of} \mathrm{the} \mathrm{lysine} \mathrm{molecules} \mathrm{are} \mathrm{bound} \mathrm{to} \mathrm{the} \mathrm{surfactant.} \mathrm{This}$ number decreases to $\sim 3 \%$ at $\mathrm{pH} 11$ [30]. As seen in Figure 2, lysine has a net positive charge at $\mathrm{pH} 7$, allowing for stronger electrostatic interactions between lysine and the negatively charged surfactants. However, this attraction is significantly reduced as it is subjected to higher $\mathrm{pH}$ levels. 


\subsection{Separation of BNP Enantiomers}

The separation of the BNP enantiomers via MEKC with und-Leu surfactants in the presence of lysine and sodium counterions were compared at $\mathrm{pH} 7$ and 11. The resolution and k' values of the BNP enantiomers are shown in Figure 3(a), Figure 3(b). Enantiomeric separation improves as the surfactant concentration increases from 15 to $45 \mathrm{mM}$ in the presence of lysine counterions at $\mathrm{pH}$ 7. At the same $\mathrm{pH}$, the best resolution observed with sodium counterions was $\sim 0.6$ at 40 $\mathrm{mM}$. This resolution was better in the presence of lysine, which was $\sim 1.1$ at 45 $\mathrm{mM}$. The separation of BNP enantiomers significantly decreased at $\mathrm{pH} 11$ in the presence of both, sodium and lysine counterions. As previously mentioned, a possible contributing factor is that at lower $\mathrm{pH}$ levels, lysine counterions have a net positive charge, allowing for stronger electrostatic attraction to occur intermolecularly with the negatively charged surfactant head groups, compared higher $\mathrm{pH}$ levels.

The enantiomers of BNP were separated with a resolution of $\sim 2.0$ at a surfactant concentration of $30 \mathrm{mM}$ at $\mathrm{pH} 7$ in the presence of lysine, whereas no separation was observed at the same $\mathrm{pH}$ and concentrations in the presence of sodium. Comparing retention factors in Figure 4(b) shows that the enantiomers of BNP interact stronger with und-Leu in the presence of lysine counterions than that of sodium counterions. At $\mathrm{pH} 7$ and $45 \mathrm{mM}$ surfactant concentration of und-Leu, a k' value of 5.8 was observed with lysine present, which is significantly higher than the $k^{\prime}$ value of 1.1 when sodium was utilized as the counterion. The difference in the influence of lysine counterions with und-Leu surfactant as compared to sodium is demonstrated in the electropherogram shown in Figure 5. Baseline resolution of BNP enantiomers was achieved at $\mathrm{pH} 7$ with a surfactant concentration of $25 \mathrm{mM}$ in the presence of Lysine, producing a k' value of $\sim 1.54$. In contrast, baseline separation was not observed in the presence of sodium counterions. As previously reported by Lewis et al., the physical properties of und-Leu in the presence of Lysine and sodium are quite different [30]. The critical micelle concentration (CMC) was determined to be $\sim 17-18 \mathrm{mM}$ in the presence of either counterion. However, at $\mathrm{pH} 7$, the hydrodynamic radius $\left(\mathrm{R}_{\mathrm{h}}\right)$ of und-Leu is larger in the presence of Lysine, than that of sodium. The $\mathrm{R}_{\mathrm{h}}$ values in Lewis et al. were reported to be $\sim 12.8 \AA$ and $\sim 10.9 \AA$ for lysine and sodium counterions, respectively [30]. The difference in chiral recognition in the presence of lysine may be due to the interactions of this counterion with the charged head groups of the surfactants. Lysine counterions are positively charged at $\mathrm{pH}$ 7, which may participate in electrostatic attractions and hydrogen bonding interactions with the micelle at this $\mathrm{pH}$, attributing to the improvement in chiral selectivity of the BNP enantiomers, as shown in Figure 6. Contrarily, at $\mathrm{pH} 11$, lysine has an overall net charge of zero thus losing its charged properties to act as an effective counterion. Due to the loss of positive charges, we therefore expect it to have less electrostatic and hydrogen bonding interactions with the negativelycharged surfactants. This is due to lysine losing its effectiveness as a counterion 


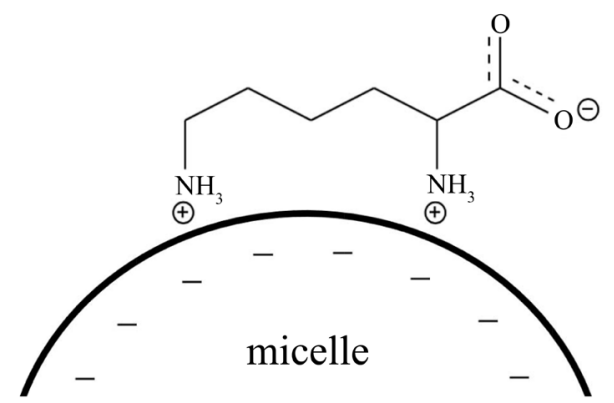

Figure 6. At $\mathrm{pH} 7$, Lysine has a net charge of +2 , therefore it is able to act as a counterion, bridging anionic surfactant head groups. Intermolecular bonding is not evident with sodium as it is monatomic.

at higher $\mathrm{pH}$ levels, which causes sodium ions to then act as the predominant counterion. Moreover, the interaction of BNP enantiomers with und-Leu is similar in the presence of sodium or neutralized lysine. Further evidence of similar interactions is shown in Figure 3(b), where similar retention factors for BNP were observed when comparing the presence of sodium or lysine counterions.

\subsection{Separation of BNA Enantiomers}

Similar to BNP, the BNA enantiomers exhibited better separation in the presence of lysine at $\mathrm{pH} 7$. At $\mathrm{pH} 7$, resolutions of 1.8, 2.0, 2.4 and 2.5 were observed at $15,25,35$ and $45 \mathrm{mM}$, respectively, in the presence of lysine counterions, as presented in Figure 4(a). These resolution values far exceed those observed in the presence of sodium at the same $\mathrm{pH}$ level. As seen in Figure 4(a), the BNA enantiomers were separated with resolutions of $0.4,0.9,1.6$ and 2.1 at concentrations of 15, 25, 35 and $45 \mathrm{mM}$, respectively in the presence of sodium counterions. As previously mentioned, the CMC of und-Leu is approximately the same $(\sim 17-18 \mathrm{mM})$ in the presence of sodium and lysine. However, at $\mathrm{pH} 7$, baseline separation of BNA enantiomers was observed at $15 \mathrm{mM}$. Furthermore, the $\mathrm{k}$ ' values indicate that BNA enantiomers do not bind strongly to und-Leu at this surfactant concentration. Overall, the interaction of BNA enantiomers is very effective at low $\mathrm{pH}$ levels and low surfactant concentrations. Below the CMC, lysine counterions still interact with und-Leu surfactants. At $\mathrm{pH}$ 7, lysine molecules are positively charged, therefore, electrostatic attraction between the positively charged amine moieties of lysine and the negatively charged und-Leu draw these two molecules closer together. This allows lysine to form hydrogen bonds with the surfactant polar head groups thus providing a chiral cavity that can improve its chiral selectivity of BNA enantiomers.

\subsection{Effect of Lysine Chirality on Chiral Recognition}

To determine if the chirality of lysine played a role in chiral recognition, two experiments were performed. In one experiment, $50 \mathrm{mM}$ L-Lysine was used without und-Leu, and no chiral recognition was observed. In another experi- 
ment, $20 \mathrm{mM}$ D-lysine and $20 \mathrm{mM}$ L-und-leu were used as the running buffer in MEKC. No difference in chiral recognition of BNA enantiomers was observed when either D- or L-Lysine was utilized as the counterion. We hypothesize that Lysine counterions may form small aggregates that provide an environment for selective chiral recognition of BNA enantiomers. If this hypothesis holds true, then using D-Lysine as the counterion should make a difference in the resolution of BNA enantiomers. Therefore, aggregates formed by D-Lysine should act in an opposite manner of L-Lysine, resulting in either reversal of enantiomeric order or reduction of resolution value. This was not observed when D-Lysine was used as the counterion.

\section{Conclusions}

The enantiomeric resolution of BNP significantly improved in the presence of lysine counterions as compared to sodium counterions at $\mathrm{pH} 7$ when using und-Leu surfactants as the chiral recognition medium. Most notably, when using a surfactant concentration of $45 \mathrm{mM}$ in the presence of lysine counterions at $\mathrm{pH} 7$, the enantiomeric resolution increased approximately 6-fold compared to that of when using sodium as the counterion. Furthermore, at the same conditions, the retention factor increased approximately 4-fold when using lysine counterions, as compared to using sodium. However, with experimental conditions at $\mathrm{pH} \mathrm{11,} \mathrm{the} \mathrm{enantiomeric} \mathrm{resolution} \mathrm{and} \mathrm{retention} \mathrm{factor} \mathrm{are} \mathrm{nearly} \mathrm{iden-}$ tical when separating BNP enantiomers with either lysine or sodium counterions.

At $\mathrm{pH} 7$, the enantiomeric resolution of BNA enantiomers was achieved using und-Leu surfactants in the presence of lysine counterions. This improved the enantiomeric resolution values as compared to when using sodium counterions. For example, at a surfactant concentration of $45 \mathrm{mM}$ in the presence of lysine at $\mathrm{pH} 7$, the enantiomeric resolution increased approximately 1.1-fold compared to that of when using sodium counterions. Furthermore, the retention factor at those same aforementioned conditions increased approximately 3.5-fold when using lysine as the counterion, as compared to using sodium. When separating BNA enantiomers using $45 \mathrm{mM}$ concentration of und-Leu surfactant at $\mathrm{pH} 11$, the enantiomeric resolution and retention factors are nearly identical to that of when using sodium as the counterion.

In conclusion, when separating chiral compounds such as BNA and BNP with und-Leu surfactants in the presence of $\mathrm{pH}$-dependent counterions such as Lysine via MEKC, the enantiomeric resolution and retention factors significantly improved when compared to using sodium counterion as the counterion in these studies. Therefore, this study provides insight to further optimize chiral separation conditions using $\mathrm{pH}$-dependent counterions as opposed to monatomic counterions such as sodium.

\section{Acknowledgements}

This work was supported by the following by NSF grants under grant numbers; 
1708959, 1709394, and 1709680. The research was also supported by a Robert A. Welch Chemistry Departmental Grant awarded to Texas A\&M University Corpus Christi Chemistry Program. In addition, Dr. Kevin Morris acknowledges the generosity of the Ralph E. Klingenmeyer family.

\section{Conflicts of Interest}

The authors declare no conflicts of interest regarding the publication of this paper.

\section{References}

[1] Gou, K., Wang, Y., Xie, L., Guo, X., Guo, Y., Ke, J., Wu, L., Li, S. and Li, H. (2020) Synthesis, Structural Properties, Biosafety and Applications of Chiral Mesoporous Silica Nanostructures. Chemical Engineering Journal, 127862. (In Press) https://doi.org/10.1016/j.cej.2020.127862

[2] Ma, Y., Shi, L., Yue, H. and Gao, X. (2020) Recognition at Chiral Interfaces: From Molecules to Cells. Colloids and Surfaces B: Biointerfaces, 195, 111268. https://doi.org/10.1016/j.colsurfb.2020.111268

[3] Wu, Q., Lv, H. and Zhao, L. (2020) Applications of Carbon Nanomaterials in Chiral Separation. TrAC Trends in Analytical Chemistry, 129, 115941. https://doi.org/10.1016/j.trac.2020.115941

[4] Tohala, L., Oukacine, F., Ravelet, C. and Peyrin, E. (2015) Chiral Resolution Capabilities of DNA Oligonucleotides. Analytical Chemistry, 87, 5491-5495. https://doi.org/10.1021/acs.analchem.5b01252

[5] Liang, R.-P., Wang, X.-N., Liu, C.-M., Meng, X.-Y. and Qiu, J.-D. (2014) Facile Preparation of Protein Stationary Phase Based on Polydopamine/Graphene Oxide Platform for Chip-Based Open Tubular Capillary Electrochromatography Enantioseparation. Journal of Chromatography A, 1323, 135-142. https://doi.org/10.1016/j.chroma.2013.11.048

[6] Kondepudi, D. (2018) Chapter 1-Chiral Asymmetry in Nature. In: Polavarapu, P. L., Ed., Chiral Analysis, 2nd Edition, Elsevier, Amsterdam, 3-28. https://doi.org/10.1016/B978-0-444-64027-7.00001-X

[7] Battisti, U.M., Citti, C., Larini, M., Ciccarella, G., Stasiak, N., Troisi, L., Braghiroli, D., Parenti, C., Zoli, M. and Cannazza, G. (2016) "Heart-Cut" Bidimensional Achiral-Chiral Liquid Chromatography Applied to the Evaluation of Stereoselective Metabolism, in Vivo Biological Activity and Brain Response to Chiral Drug Candidates Targeting the Central Nervous System. Journal of Chromatography A, 1443, 152-161. https://doi.org/10.1016/j.chroma.2016.03.027

[8] Du, Z., Liu, C., Song, H., Scott, P., Liu, Z., Ren, J. and Qu, X. (2020) Neutrophil-Membrane-Directed Bioorthogonal Synthesis of Inflammation-Targeting Chiral Drugs. Chem, 6, 2060-2072. https://doi.org/10.1016/j.chempr.2020.06.002

[9] Ding, F., Peng, W., Peng, Y.-K. and Liu, B.-Q. (2020) Estimating the Potential Toxicity of Chiral Diclofop-Methyl: Mechanistic Insight into the Enantioselective Behavior. Toxicology, 438, 152446. https://doi.org/10.1016/j.tox.2020.152446

[10] Lalitha, S., Sampath Kumar, A., Stine, K.J. and Covey, D.F. (2001) Chirality in Membranes: First Evidence that Enantioselective Interactions between Cholesterol and Cell Membrane Lipids Can Be a Determinant of Membrane Physical Properties. Journal of Supramolecular Chemistry, 1, 53-61. https://doi.org/10.1016/S1472-7862(01)00013-2 
[11] Dong, L., Gong, J., Wang, Y., He, J., You, D., Zhou, Y., Li, Q., Liu, Y., Cheng, K., Qian, J., Weng, W., Wang, H. and Yu, M. (2019) Chiral Geometry Regulates Stem Cell Fate and Activity. Biomaterials, 222, 119456. https://doi.org/10.1016/j.biomaterials.2019.119456

[12] Wang, M., Jiang, W., Liu, X., Wang, J., Zhang, B., Fan, C., Liu, L., Pena-Alcantara, G., Ling, J.-J., Chen, J. and Zhu, T.F. (2019) Mirror-Image Gene Transcription and Reverse Transcription. Chem, 5, 848-857. https://doi.org/10.1016/j.chempr.2019.01.001

[13] Nguyen, L. A., He, H. and Pham-Huy, C. (2006) Chiral Drugs: An Overview. International Journal of Biomedical Science, 2, 85-100.

[14] Rentsch, K.M. (2002) The Importance of Stereoselective Determination of Drugs in the Clinical Laboratory. Journal of Biochemical and Biophysical Methods, 54, 1-9. https://doi.org/10.1016/S0165-022X(02)00124-0

[15] McConathy, J. and Owens, M.J. (2003) Stereochemistry in Drug Action. Primary Care Companion to the Journal of Clinical Psychiatry, 5, 70-73. https://doi.org/10.4088/PCC.v05n0202

[16] Brooks, W.H., Guida, W.C. and Daniel, K.G. (2011) The Significance of Chirality in Drug Design and Development. Current Topics in Medicinal Chemistry, 11, 760-770. https://doi.org/10.2174/156802611795165098

[17] Burley, D.M. and Lenz, W. (1962) Thalidomide and Congenital Abnormalities. The Lancet, 279, 271-272. https://doi.org/10.1016/S0140-6736(62)91217-5

[18] Melchert, M. and List, A. (2007) The Thalidomide Saga. The International Journal of Biochemistry \& Cell Biology, 39, 1489-1499. https://doi.org/10.1016/j.biocel.2007.01.022

[19] Liu, J.-T. and Liu, R.H. (2002) Enantiomeric Composition of Abused Amine Drugs: Chromatographic Methods of Analysis and Data Interpretation. Journal of Biochemical and Biophysical Methods, 54, 115-146. https://doi.org/10.1016/S0165-022X(02)00136-7

[20] Wright, A.K., Batsomboon, P., Dai, J., Hung, I., Zhou, H.-X., Dudley, G.B. and Cross, T.A. (2016) Differential Binding of Rimantadine Enantiomers to Influenza A M2 Proton Channel. Journal of the American Chemical Society, 138, 1506-1509. https://doi.org/10.1021/jacs.5b13129

[21] Morris, K.F., Billiot, E.J., Billiot, F.H., Lipkowitz, K.B., Southerland, W.M. and Fang, Y. (2013) A Molecular Dynamics Simulation Study of Two Dipeptide Based Molecular Micelles: Effect of Amino Acid Order. Open Journal of Physical Chemistry, 3, 20-29. https://doi.org/10.4236/ojpc.2013.31004

[22] Morris, K.F., Billiot, E.J., Billiot, F.H., Ingle, J.A., Krause, K.B., Lewis, C.R., Lipkowitz, K.B., Southerland, W.M. and Fang, Y. (2019) Using Molecular Dynamics Simulations to Identify the Key Factors Responsible for Chiral Recognition by an Amino Acid-Based Molecular Micelle. Journal of Dispersion Science and Technology, 40, 716-727. https://doi.org/10.1080/01932691.2018.1479267

[23] (1992) FDA's Policy Statement for the Development of New Stereoisomeric Drugs. Chirality, 4, 338-340. https://doi.org/10.1002/chir.530040513

[24] Konjaria, M.-L. and Scriba, G.K.E. (2020) Enantioseparation of Alanyl-Phenylalanine Analogs by Capillary Electrophoresis Using Negatively Charged Cyclodextrins as Chiral Selectors. Journal of Chromatography A, 1632, 461585. https://doi.org/10.1016/j.chroma.2020.461585

[25] Lee, S., Kim, S.-J., Bang, E. and Na, Y.-C. (2019) Chiral Separation of Intact Amino Acids by Capillary Electrophoresis-Mass Spectrometry Employing a Partial Filling 
Technique with a Crown Ether Carboxylic Acid. Journal of Chromatography A, 1586, 128-138. https://doi.org/10.1016/j.chroma.2018.12.001

[26] Sánchez-Hernández, L., Castro-Puyana, M., Marina, M.L. and Crego, A.L. (2012) Recent Approaches in Sensitive Enantioseparations by CE. Electrophoresis, 33, 228-242. https://doi.org/10.1002/elps.201100404

[27] Zhu, X., Chen, C., Chen, J., Xu, G., Du, Y., Ma, X., Sun, X., Feng, Z. and Huang, Z. (2020) Synthesis and Application of Tetramethylammonium-Carboxymethylated$\beta$-Cyclodextrin: A Novel Ionic Liquid in Capillary Electrophoresis Enantioseparation. Journal of Pharmaceutical and Biomedical Analysis, 180, 113030. https://doi.org/10.1016/j.jpba.2019.113030

[28] Datta, R. (1990) Theoretical Evaluation of Capillary Electrophoresis Performance. Biotechnology Progress, 6, 485-493. https://doi.org/10.1021/bp00006a012

[29] Engelhardt, H. and Cunat-Walter, M.A. (1995) Use of Plate Numbers Achieved in Capillary Electrophoretic Protein Separations for Characterization of Capillary Coatings. Journal of Chromatography $A, 717,15-23$.

https://doi.org/10.1016/0021-9673(95)00485-7

[30] Lewis, C., Hughes, B.H., Vasquez, M., Wall, A.M., Northrup, V.L., Witzleb, T.J., Billiot, E.J., Fang, Y., Billiot, F.H. and Morris, K.F. (2016) Effect of $\mathrm{pH}$ on the Binding of Sodium, Lysine, and Arginine Counterions to L-Undecyl Leucinate Micelles. Journal of Surfactants and Detergents, 19, 1175-1188. https://doi.org/10.1007/s11743-016-1875-y

[31] Billiot, A., Fang, Y. and Morris, K. (2019) Characterization of Amino Acid Based Molecular Micelles with Molecular Modeling. Open Journal of Physical Chemistry, 9, 221-240. https://doi.org/10.4236/ojpc.2019.94014

[32] Billiot, E., Macossay, J., Thibodeaux, S., Shamsi, S.A. and Warner, I.M. (1998) Chiral Separations Using Dipeptide Polymerized Surfactants: Effect of Amino Acid Order. Analytical Chemistry, 70, 1375-1381. https://doi.org/10.1021/ac9709561

[33] Haddadian, F., Billiot, E.J., Shamsi, S.A. and Warner, I.M. (1999) Chiral Separations Using Polymeric Dipeptide Surfactants: Effect of Number of Chiral Centers and Steric Factors. Journal of Chromatography A, 858, 219-227. https://doi.org/10.1016/S0021-9673(99)00810-9

[34] Ramos, Z., Rothbauer, G.A., Turner, J., Lewis, C., Morris, K., Billiot, E., Billiot, F. and Fang, Y. (2019) Comparison of Chiral Recognition of Binaphthyl Derivatives with L-Undecyl-Leucine Surfactants in the Presence of Arginine and Sodium Counterions. Journal of Chromatographic Science, 57, 54-62.

https://doi.org/10.1093/chromsci/bmy080

[35] Tackie-Otoo, B.N. and Ayoub Mohammed, M.A. (2020) Experimental Investigation of the Behaviour of a Novel Amino Acid-Based Surfactant Relevant to EOR Application. Journal of Molecular Liquids, 316, 113848.

https://doi.org/10.1016/j.molliq.2020.113848

[36] Fawzy, A., Abdallah, M., Zaafarany, I.A., Ahmed, S.A. and Althagafi, I.I. (2018) Thermodynamic, Kinetic and Mechanistic Approach to the Corrosion Inhibition of Carbon Steel by New Synthesized Amino Acids-Based Surfactants as Green Inhibitors in Neutral and Alkaline Aqueous Media. Journal of Molecular Liquids, 265, 276-291. https://doi.org/10.1016/j.molliq.2018.05.140

[37] Pinazo, A., Manresa, M.A., Marques, A.M., Bustelo, M., Espuny, M.J. and Pérez, L. (2016) Amino Acid-Based Surfactants: New Antimicrobial Agents. Advances in Colloid and Interface Science, 228, 17-39. https://doi.org/10.1016/j.cis.2015.11.007

[38] Perinelli, D.R., Casettari, L., Cespi, M., Fini, F., Man, D.K.W., Giorgioni, G., Canala, 
S., Lam, J.K.W., Bonacucina, G. and Palmieri, G.F. (2016) Chemical-Physical Properties and Cytotoxicity of N-Decanoyl Amino Acid-Based Surfactants: Effect of Polar Heads. Colloids and Surfaces A: Physicochemical and Engineering Aspects, 492, 38-46. https://doi.org/10.1016/j.colsurfa.2015.12.009

[39] Pinazo, A., Pons, R., Pérez, L. and Infante, M.R. (2011) Amino Acids as Raw Material for Biocompatible Surfactants. Industrial \& Engineering Chemistry Research, 50, 4805-4817. https://doi.org/10.1021/ie1014348

[40] Clapés, P. and Rosa Infante, M. (2002) Amino Acid-Based Surfactants: Enzymatic Synthesis, Properties and Potential Applications. Biocatalysis and Biotransformation, 20, 215-233. https://doi.org/10.1080/10242420290004947

[41] Billiot, F.H., Billiot, E.J. and Warner, I.M. (2002) Depth of Penetration of Binaphthyl Derivatives into the Micellar Core of Sodium Undecenoyl Leucyl-Leucinate Surfactants. Journal of Chromatography A, 950, 233-239.

https://doi.org/10.1016/S1570-0232(02)00008-9 